\title{
Half Protons or Doubly Charged Protons? The History of Metastable Ions
}

\author{
Herbert Budzikiewicz \\ Institut für Organische Chemie der Universität zu Köln, Cologne, Germany \\ Ronald D. Grigsby \\ PetroMass, Norman, Oklahoma, USA
}

\begin{abstract}
The history of metastable ions is intertwined with that of ions formed by collision-induced dissociation (CID), and frequently the genesis of the two ion types cannot be strictly separated. Originally, metastable ions were considered a curiosity or even a nuisance, being responsible for "humps" in the base line of the recorded mass spectra. In their heyday metastable ions were recognized as having importance for establishing fragmentation sequences and for distinguishing between isomeric ion structures. Today, in many respects the utility of metastable ions has been superseded by a systematic application of CID techniques; yet the evaluation of their shape is still of importance for questions of reaction energies and ion thermochemistry. (J Am Soc Mass Spectrom 2004, 15, 1261-1265) @ 2004 American Society for Mass Spectrometry
\end{abstract}

$\mathrm{D}$ uring the early development of mass spectrometry, an unexpected peak at $m / z^{1 / 2}$ was occasionally observed in the mass spectra of hydrogen, in addition to the peaks at $m / z 1,2$, and 3 easily attributable to $\mathrm{H}^{+}, \mathrm{H}_{2}^{+}$, and $\mathrm{H}_{3}^{+}$. Researchers at the time were puzzled to explain this spurious "band" that was frequently accompanied by a less abundant one recorded at $m / z^{1 / 3}$ in a parabola mass spectrograph.

Explanations for the fractional masses are to be found in experiments with canal rays dating back at least to 1902 [1]. F. Paschen reported in 1907 that two maxima were sometimes observed in the Doppler curve for the emission spectrum of hydrogen [2]. He suggested that the displacements of the lines could be explained by the presence of monatomic and triatomic molecules of hydrogen in the canal rays. Paschen's observation was confirmed by experiments of J. Stark and W. Steubing (1909) [3] and by those of B. Strasser (1910) [4], who recorded the Doppler curve for the $\mathrm{H}_{\gamma}$ line of the Balmer series. E. Gehrcke and O. Reichenheim [5] suggested that the line spectra of the hydrogen atom and molecule are the same with the most deflected maximum of the Doppler curve arising from the atom and the other from the molecule. They assumed that $\mathrm{H}^{+}$ and $\mathrm{H}_{2}^{+}$must fall through the same potential difference and thus acquire the same kinetic energy: $1 / 2 m_{1} \nu_{1}^{2}$ $=1 / 2 m_{2} \nu_{2}^{2}$ with $m_{1}=1$ and $m_{2}=2$. In their experi-

Published online July 28, 2004

Address reprint requests to Dr. H. Budzikiewicz, Institut für Organische Chemie der Universität zu Köln, Greinstr. 4, 50939 Cologne, Germany. E-mail: h.budzikiewicz@uni-koeln.de ments, Gehrcke and Reichenheim found that the ratio of the displacements of the two maxima was approximately $1: \sqrt{2}$, as predicted. However, Stark [6] questioned their explanation because the ratios reported by various researchers varied between 1.37 and 1.75 . In his opinion, the deviations from 1.41 were too much to be explained by experimental error. [The Stark effect was not discovered until 1913. As distinct from the Doppler effect, it is the splitting of lines caused by an induced dipole moment through interaction of atoms and molecules with an external field of high intensity, e.g., 100,000 V/cm. Stark was awarded the 1919 Nobel Prize in Physics for the discovery that bears his name.] As a further argument against the suggested interpretation given by Gehrcke and Reichenheim, Stark mentions that he and Steubing as well as Strasser had observed a third intensity maximum in the Doppler curve corresponding to $m / z^{1 / 2}$, leading him to proffer the question: "Soll dieses von Wasserstoffatomen herrühren, welche die Ladung zweier positiver Quanten oder nur die halbe Masse des Wasserstoffatoms für ein positives Quantum haben?" ["Should it stem from hydrogen atoms having a charge of two positive quanta or from half the mass of the hydrogen atom with one positive quantum?"] To our knowledge this is the first mention of the phenomenon which prima facie would suggest the existence of half protons or doubly charged protons.

Without providing any details, Stark goes on to say 
that for a long time the above considerations had induced him to reject the suggested interpretation of the intensity distribution in the Doppler curve and to seek its cause in an "energetic regularity of the light emission" [6].

In a 1913 book, J. J. Thomson states that the Doppler curve for the emission spectrum of hydrogen should have the same variations in intensity as the parabola in the mass spectrum with as many maxima in the Doppler curve as there are beads on the parabola [7]; see also [8]. Furthermore, he notes that it is not necessary to assume that the hydrogen atom and molecule give out the same lines in the emission spectrum. Thus explanations for the maxima in the Doppler curve of hydrogen are found to apply as well to the "beads" in the parabola mass spectrum of hydrogen.

In the same 1913 book Thomson presents a number of parabola mass spectra in which a "beading" is clearly evident. An example is shown in Figure 1. He observes that apparently $\mathrm{H}^{+}$is traveling with two velocities in a ratio of $1 / \sqrt{2}$, indicating that the ions with the higher velocity stem from original $\mathrm{H}^{+}$and the others from $\mathrm{H}_{2}^{+}$ being fully accelerated but decomposing to $\mathrm{H}^{+}$before being deflected. The velocity ratio follows from the same considerations as outlined above. The momentum of the slower $\mathrm{H}^{+}$ions would be $1 / \sqrt{2}$ times the momentum of the original $\mathrm{H}^{+}$ions, resulting in a peak appearing at $m / z^{1 / 2}$ in the recorded mass spectrum.

Citing his results presented in a 1919 lecture, F. W. Aston describes in a 1920 paper [9] a brightening ("beading") of the parabolas of $\mathrm{H}^{+}$and $\mathrm{H}^{-}$in the mass spectrum of $\mathrm{H}_{2}$ at places where hydrogen ions with half the kinetic energy, corresponding to half the mass, would be expected. The process $\mathrm{H}_{2}^{+}+\mathrm{e}^{-} \rightarrow \mathrm{H}^{+}+\mathrm{H}^{-}$ is invoked as an explanation of this "beading". Ironically, in the first (1922) and second edition (1924) of Aston's book Isotopes [10], the band at $m / z 1 / 2$ is not mentioned, and it cannot be seen in the hydrogen spectra depicted there.

In two publications (1924 and 1925), H. D. Smyth discusses in detail the various reactions taking place after ionization of $\mathrm{H}_{2}[11,12]$. Following the laws of conservation of momentum and energy, he points out that dissociation of $\mathrm{H}_{2}^{+}$is fostered by collision processes and that dissociation after electrostatic acceleration but before mass separation in the magnetic field will lead to the signals appearing at fractional masses. Using a $180^{\circ}$ magnetic-deflection instrument equipped with a Faraday cylinder and electrometer, Smyth recorded the pressure-dependent mass spectrum of hydrogen, showing the fractional peaks at $m / z 1 / 2$ and $1 / 3$ as well as the peaks at $m / z 1,2$, and 3 [12].

J. Mattauch and H. Lichtblau, in a detailed study published in 1939 [13], attribute the discovery of the so-called "Astonschen Banden" to Aston, referring to his 1933 book Mass Spectra and Isotopes [14]. In a 1955 Russian study [15] on the formation of $m / z \frac{1}{2}$, reference is made only to the 1939 paper by Mattauch and

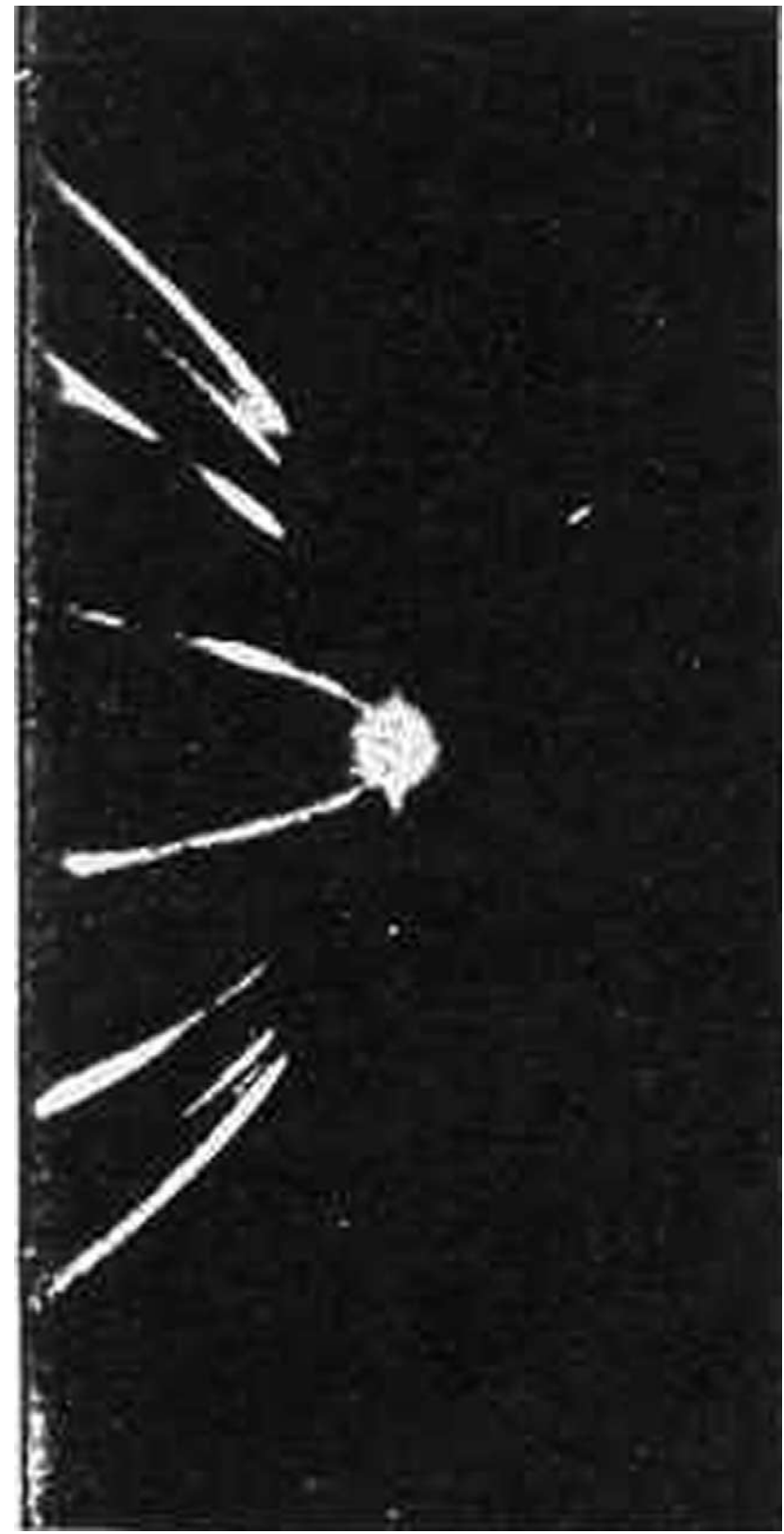

Figure 1. Early photoplate recording of the mass spectrum of hydrogen showing beads in the parabolas corresponding to groups of ions moving with approximately the same velocity. Reproduced from Figure 17, Plate I in reference [7].

Lichtblau. Thus it seems that Mattauch and Lichtblau, as well as others, have attributed explanation of the bands misleadingly to Aston when in fact they had been explained earlier by Thomson and Smyth.

Apparently, interest in the Aston bands was marginal. Referring to the bands resulting from the dissociation of the hydrogen molecule and the carbon monoxide molecule, Aston states in his 1933 book: "Both the bands disappear completely when the pressure in the camera is sufficiently reduced, supporting the view that they are purely secondary effects and therefore not to be seriously considered in connection with the interpretation of mass-spectra." 


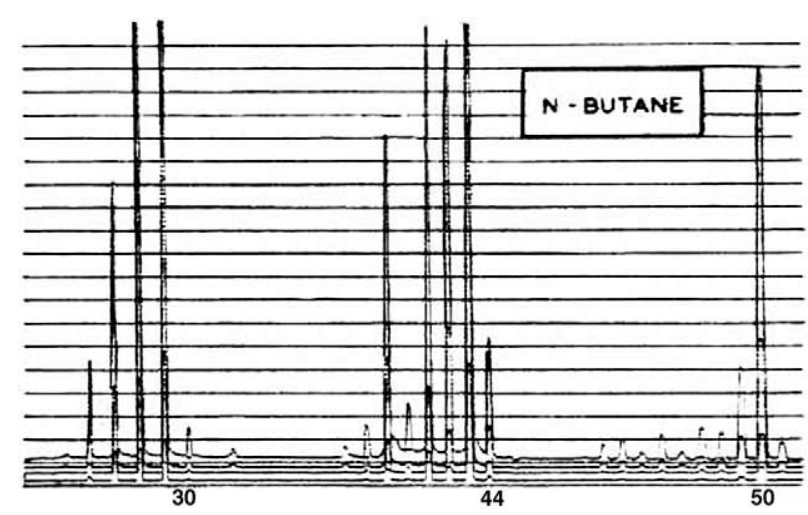

Figure 2. Mass spectrum of $n$-butane, showing a metastable peak at $m / z$ 39.2. Reproduced in part with permission from Ind. Eng. Chem. Anal. Ed. 1943, 15, 541-547, Copyright 1943, Am. Chem. Soc.

In a special feature article, published in 1995, R. G. Cooks [16] provides a detailed history of collisioninduced dissociation (CID) up to 1970. A number of quotations and figures from the early work are included, such as the electronically recorded mass spectrum of hydrogen appearing in the 1925 paper by Smyth [12].

Evidently, the early observations of fractional masses in the spectra of simple molecules are explained mostly by CID rather than unimolecular decomposition. The recognition of truly unimolecular decomposition of ions in the region between the electric and magnetic fields of a mass spectrometer is usually ascribed to J. A. Hipple and coworkers $[17,18]$. In reference to the mass spectrum of $n$-butane, they state [17]: "The 'hump' on the side of the peak at mass 39 has not previously been investigated carefully but was usually attributed to the formation of $\mathrm{C}_{3} \mathrm{H}_{3}^{+}$with kinetic energy." However, they give no literature reference to this statement and mention only a 1943 publication by H. W. Washburn and coworkers [19] from which an $n$-butane mass spectrum showing this "hump" is reproduced. See Figure 2. In their detailed study [18], Hipple and coworkers prove that the decomposition of metastable ions can occur in the field-free region and show that the apparent mass can be calculated by the equation $m^{*}=\mathrm{m}^{2} / m_{\mathrm{o}}$. (The "hump" on the side of $\mathrm{m} / \mathrm{z} 39$ comes from the loss of $\mathrm{H}_{2}$ from $\mathrm{C}_{3} \mathrm{H}_{7}^{+}: 41^{2} / 43=39.1$.)

Note that Hipple and Condon [17] calculate the mass as 39.2 instead of 39.1. The difference may be attributable to "slide rule error." On the other hand, the metastable peak may actually have been recorded at 39.2. The familiar equation $m^{*}=m^{2} / m_{\mathrm{o}}$ is approximate. More detailed equations taking into account the release of internal energy are found in the literature [20,21].

Hipple and coworkers are the first to speak of metastable ions in the context that unstable ions decompose in the ion source, stable ions reach the collector, and metastable ions decompose in between. They distinguish clearly between the "metastable ion" and the "broad" or "diffuse" peak recorded in the spectrum.
Later on, in a somewhat careless manner, the term "metastable peak" came into use and according to IUPAC [22] this usage should be retained. J. Seibl [23] suggests using the term "Übergangssignale" (transition signals), which can be found occasionally in the literature.

Notwithstanding some interest by physicists, the appearance of metastable peaks in the mass spectra was generally considered a nuisance. In the days before gas chromatography was established as a routine analytical method, qualitative and quantitative analyses of hydrocarbon mixtures in the petroleum industry were performed by tedious evaluations of mass spectra obtained under standardized conditions. Here the "humps" in the baseline were certainly of no help. Because the products of metastable-ion decomposition have less kinetic energy than fully accelerated ions, they will not reach the collector if a retarding potential is applied to an electrode placed in the ion path. Consolidated Electrodynamics Corporation (CEC) mass spectrometers, which were widely used in the laboratories of oil companies at the time, had a metastable suppressor of this kind as a standard part.

The esteem for metastable ions rose sharply in the 1960s when much interest existed in the rationalization of fragmentation processes. At that time mass spectrometry was used increasingly for the structure elucidation of compounds, especially in the field of natural products. The observation of a metastable peak offered the primary evidence for connecting a fragment ion with its precursor. The slide rule or a nomogram (see [20], Appendix 2), tools almost forgotten today, were used to provide an easy means for quickly finding all possible mass combinations of fragment and precursor ions to explain a given metastable peak. The prevailing opinion expressed in the textbooks of the period was that the neutral lost from a metastable ion, ignoring hydrogen migrations, was also an entity in the precursor ion. For further discussion see Seibl [23], K. R. Jennings [24], and H. Budzikiewicz et al. [25], who demonstrate that a common metastable peak can be observed for two fast consecutive losses, especially when metastable peaks are observed for the single steps. Probably the most widely encountered example is provided by the metastable peaks for the stepwise (in either sequence) and combined losses of $\mathrm{H}_{2} \mathrm{O}$ and $\mathrm{CH}_{3}$ from hydroxy steroids. A theoretical treatment for combined losses is given by J. L. Holmes et al. [26]. The existence of interacting ion/neutral pairs after fragmentation [27] may play an important role for combined losses. The first example for such interactions to be found in the literature is probably the [phenyl/cyclopropane $]^{+}$complex [28]. The important role these complexes play in understanding fragmentation processes, especially the decomposition of metastable ions, was brought to the attention of mass spectrometrists only after the discussion of exchange reactions between the two amino functions of 3,20-diamino steroids by $\mathrm{P}$. Longevialle and coworkers, who provide evidence for these intermediates $[29,30]$. 
The observation that metastable peaks were broader than those of the primary ions formed in the ion source was explained almost from the beginning by the release of internal energy during fragmentation. As the width of the peaks can be correlated with the amount of energy given off [31], information about the reverse activation energy for a fragmentation process or for inter-charge distances in doubly charged ions can be gained-an area of research still of interest [32-34].

Instrument designers are usually aware of changes in their customers' interests. For example, CEC provided metastable suppressors on their 21-100 (Dempster) series of instruments. Around 1970, the new appreciation of metastable ions induced Atlas MAT (Atlas Mess-und Analysentechnik $\mathrm{GmbH}$, later FinniganMAT, now ThermoElectron Corporation) to install in their 701/731 instruments a proportionally over-long drift tube between the ion source and the electrostatic sector, thus allowing an enhanced observation of metastable peaks arising from ions decomposing in the first field-free region.

A major drawback in the use of metastable peaks to establish ion-fragmentation sequences became apparent, especially for larger molecules: i.e., more than one pair of ionic masses can satisfy the equation $m^{*}=$ $\mathrm{m}^{2} / \mathrm{m}_{\mathrm{o}}$. Moreover, weak signals can easily disappear into the base line of the mass spectrum. The first method for an unambiguous assignment of the relationship between parent and daughter ion was the defocusing technique [35]. When a double focusing mass spectrometer, i.e., one having electrostatic and magnetic sectors, is adjusted to pass ions of mass $m$, and the accelerating voltage $V$ is increased by a factor of $m_{\mathrm{o}} / m$, the daughter ion resulting from the decomposition of $m_{\mathrm{o}}$ in the first field-free region will pass the electrostatic sector and be detected at mass $m$ while all ions having the full kinetic energy will be deflected. Hence even weak signals can be detected. Continuous increase of $V$ results in a parent ion scan for $m$ [36]. An experimental limitation of this technique is that $V$ can be varied only by factor of about two.

A big step forward in the development of massspectrometric instrumentation was the advent of the digital data acquisition system. Not only did these systems record the spectra, they also controlled the scan functions of double focusing mass spectrometers, as well those of others. However, unlike analog recording systems-such as those designed around oscillographic recorders-digital data acquisition systems recognized only sharp peaks and thus ignored the "humps" in the spectra corresponding to metastable signals.

Two techniques became available for producing sharp metastable peaks that could be recorded with a digital data acquisition system. The older technique required a so-called inverse geometry with the magnetic sector preceding the electrostatic sector. It was presented independently in 1971 by the Finnigan-MAT team as direct analysis of daughter ions (DADI) and by Beynon and Cooks as MIKES (mass-analyzed ion ki- netic energy spectra). For details see U. P. Schlunegger [37]. Ions of a given mass are selected by the magnetic sector, and the products of their decomposition in the region between the two deflecting fields are recorded after passing through the electrostatic sector, the voltage of which is scanned.

More versatile and independent of the arrangement of the sectors are the linked-scan techniques. Simultaneous changes in the magnetic-field strength $B$ and in the deflection voltage of the electrostatic sector $E$ can be programmed in such a way that either all fragment ions arising from a given precursor $(B / E$ constant) or all precursors of a given fragment ion $\left(B^{2} / E\right.$ constant) can be recorded. The first technique gives the same results as DADI. A more complex scan function is necessary for a neutral loss scan, recording those ions that lose a given neutral, e.g., $\mathrm{H}_{2} \mathrm{O}$. Other scan functions have been devised [38]. Although originally developed for sectorfield instruments, analogous scanning techniques are available for triple quadrupole mass spectrometers.

Isomeric ions may be distinguished by the decomposition of corresponding metastable ions. Both the width of a metastable peak, as a measure of the internal energy given off, and the peak's relative abundance provide information on the structures of the ions. T. W. Shannon and F. W. McLafferty [39] demonstrate the existence of three different structures for $\mathrm{C}_{2} \mathrm{H}_{5} \mathrm{O}^{+}$ions stemming from various precursors. In a further development for the fingerprinting of ions, McLafferty and coworkers [40] describe a technique in which ions are selected and subsequently fragmented by CID in a double focusing mass spectrometer.

It was not always appreciated that ions decomposing in the ion source differ from metastable ions in the content of their internal energy and their lifetime. Conclusions drawn from investigations of the structures of long-lived ions formed with little excess energy do not apply directly to species decomposing in the ion source. Examples of the former include complex rearrangement processes such as back and forth hydrogen exchanges and skeletal reorientations. Detailed discussions at conferences and in print eventually led to an understanding of the differences in these processes. An illustrative example is provided by primary aliphatic amines. The molecular ions of $\mathrm{R}-\mathrm{CH}_{2}-\mathrm{NH}_{2}$ decompose in the ion source overwhelmingly by $\alpha$-cleavage, producing $\mathrm{CH}_{2}=\mathrm{NH}_{2}^{+}$, but the long-lived ions rearrange to $\mathrm{R}-\mathrm{CHNH}_{2}-\mathrm{CH}_{3}^{+\cdot}$ by a series of steps involving a number of hydrogen migrations and CID, resulting in the formation of $\mathrm{CH}_{3}-\mathrm{CH}=\mathrm{NH}_{2}^{+}$[41].

The history of unimolecular decomposition actually began with CID, resulting in the appearance of unexpected signals in recorded mass spectra. Ions formed by both processes were not (and are not) always distinguishable, one from the other. A current example is provided by the post-ion-source decay of ions in a MALDI-TOF mass spectrometer [42]. Interest in metastable ions climaxed during the 1960s and 1970s, but today their investigation has been replaced largely by 
studies of ions formed by CID [43]. They are usually more abundant than metastable ions and less dependent on the internal energy of the decomposing species. Furthermore, ions produced by CID can be studied, e.g., with ion traps and ion cyclotron resonance instruments in which metastable peaks cannot be observed.

This brings the circle of developments in metastableion chemistry back to the early days of the 20th century when "bands" in the mass spectra of simple molecules, such as hydrogen, were first observed.

\section{Acknowledgments}

The authors express their appreciation to the curator and staff of the History of Science Collections at the University of Oklahoma for generously providing them with access to some of the early textbooks on mass spectrometry.

\section{References}

1. Wien, W. Untersuchungen über die elektrische Entladung in verdünnten Gasen. Ann. d. Phys. Vierte Folge 1902, 8, 244-266.

2. Paschen, F. Über den Dopplereffekt im Spektrum der Kanalstrahlen des Wasserstoffs. Ann. d. Phys. Vierte Folge 1907, 23, 247-261.

3. Stark, J.; Steubing, W. Spektralanalytische Beobachtungen an Kanalstrahlen mit Hilfe großer Dispersion. Ann. d. Phys. Vierte Folge 1909, 28, 974-998.

4. Strasser, B. Beobachtungen am Dopplereffekt bei Wasserstoffkanalstrahlen. Ann. d. Phys. Vierte Folge 1910, 31, 890-918.

5. Gehrcke, E.; Reichenheim, O. Das magnetische Spektrum und das Dopplerspektrum der Kanalstrahlen. Verh. Dtsch. Phys. Ges. 1910, 12, 414-419.

6. Stark, J. Bemerkungen zu neueren Abhandlungen über Kanalstrahlen. Verh. Dtsch. Phys. Ges. 1910, 12, 711-718.

7. Thomson, J. J. Rays of Positive Electricity and their Application to Chemical Analyses; Longmans, Green, \& Co: London, 1913, pp 94-95; also Fig. 17, Plate I.

8. Thomson, J. J. Rays of Positive Electricity. Proc. Roy. Soc. 1914, A89, 1-20.

9. Aston, F. W. The Distribution of Intensity along the Positive Ray Parabolas of Atoms and Molecules of Hydrogen and its Possible Explanation. Proc. Camb. Phil. Soc. 1920, 19, 317-323.

10. Aston, F. W. Isotopes; Arnold: London, 1922, and 1924.

11. Smyth, H. D. Different Types of Ions in Hydrogen. Nature 1924, 114, 124.

12. Smyth, H. D. Primary and Secondary Products of Ionization in Hydrogen. Phys. Rev. 1925, 25, 452-468.

13. Mattauch, J.; Lichtblau, H. Banden in der Massenspektrographie. Physik. Zeitschr. 1939, 40, 16-22.

14. Aston, F. W. Mass Spectra and Isotopes; Arnold: London, 1933, pp 60-62.

15. Tuntskii, N. N.; Smirnova, R. M.; Tikhomirov, M. V. On "Fractional" Peaks in the Mass Spectra of Hydrogen. Dokl. Akad. Nauk. 1955, 101, 1083-1084.

16. Cooks, R. G. Collision-Induced Dissociation: Readings and Commentary. J. Mass Spectrom. 1995, 30, 1215-1221.

17. Hipple, J. A.; Condon, E. U. Detection of Metastable Ions with the Mass Spectrometer. Phys. Rev. 1945, 68, 54-55.

18. Hipple, J. A.; Fox, R. E.; Condon, E. U. Metastable Ions Formed by Electron Impact in Hydrocarbon Gases. Phys. Rev. 1946, 69, 347-356.

19. Washburn, H. W.; Wiley, H. F.; Rock, S. M. The Mass Spectrometer as an Analytical Tool. Ind. Eng. Chem. Anal. Ed. 1943, $15,541-547$.
20. Beynon, J. H. Mass Spectrometry and its Applications to Organic Chemistry; Elsevier: Amsterdam, 1960, pp 252, 253.

21. Beynon, J. H.; Caprioli, R. M. In Biochemical Applications of Mass Spectrometry; Waller, G. R., Ed.; Wiley: New York, 1972, Chap 5 .

22. Recommendations for the Nomenclature and Symbolism for Mass Spectroscopy. Pure Appl. Chem. 1991, 63, 1541-1566.

23. Seibl, J. Zur Kenntnis der metastabilen Übergänge in Massenspektren organischer Verbindungen. Helv. Chim. Acta 1967, 50, 263-268.

24. Jennings, K. R. Consecutive Metastable Transitions in a Double-focusing Mass Spectrometer. Chem. Commun. 1966, 9, 283 284.

25. Budzikiewicz, H.; v.d. Haar, F.; Inhoffen, H. H. Zum Aussagewert metastabiler Ionen bei Strukturermittlungen mit Hilfe von Massenspektren: Kombinierte Zerfallsreaktionen bei Chlorinen. Liebigs Ann. Chem. 1967, 701, 23-27.

26. Holmes, J. L.; Cartledge, K.; Osborne, A. D. A Monte Carlo Method for the Simulation of Consecutive Metastable Fragmentations. Int. J. Mass Spectrom. Ion Phys. 1979, 29, 171-178.

27. McAdoo, D. J. Ion-Neutral Complexes in Unimolecular Decompositions. Mass Spectrom. Rev. 1988, 7, 363-393.

28. Rylander, P. N.; Meyerson, S. Organic Ions in the Gas Phase. I. The Cationated Cyclopropane Ring. J. Am. Chem. Soc. 1956, 78, 5799-5802.

29. Longevialle, P.; Diatta, L. La fragmentation des diamines stéroïdiques et de leurs dérivés en spectrométrie de masse. Org. Mass Spectrom. 1970, 3, 803-816.

30. Longevialle, P.; Botter, R. Evidence for Intramolecular Interaction between Ionic and Neutral Fragments in the Mass Spectrometer. Chem. Commun. 1980, 17, 823-825.

31. Beynon, J. H.; Saunders, R. H.; Williams, A. E. Dissociation of Metastable Ions in Mass Spectrometers with release of Internal Energy. Z. Naturforsch. 1965, 20a, 180-183.

32. Cooks, R. G.; Beynon, J. H.; Caprioli, R. M.; Lester, G. R. Metastable Ions; Elsevier: Amsterdam, 1973, Chap. 4.

33. Holmes, J. L.; Terlouw, J. K. The Scope of Metastable Peak Observations. Org. Mass Spectrom. 1980, 15, 383-396.

34. Laskin, J.; Lifshitz, C. Kinetic Energy Release Distribution in Mass Spectrometry. J. Mass Spectrom. 2001, 36, 459-478.

35. Barber, M.; Elliot, R. M. Comparison of Metastable Spectra from Single and Double Focusing Mass Spectrometers. Proceedings of the 12th ASMS Conference; Montréal, Quebec, 1964.

36. Barber, M.; Wolstenholme, W. A.; Jennings, K. R. Metastable Ions in a Double Focusing Mass Spectrometer. Nature 1967, $214,664-666$.

37. Schlunegger, U. P. Nachweis von Fragment-Genesen im Massenspektrometer: DADI-Massenspektrometrie als Hilfsmittel zur Strukturanalyse organischer Verbindungen. Angew. Chem. $1975,87,731-740$

38. Vincenti, M.; Schwartz, J. C.; Cooks, R. G.; Wade, A. P.; Enke, C. G. The Functional Relationship Scan in Tandem Mass Spectrometry. Org. Mass Spectrom. 1988, 23, 579-584.

39. Shannon, T. W.; McLafferty, F. W. Identification of Gaseous Organic Ions by the Use of "Metastable Peaks." J. Am. Chem. Soc. 1966, 88, 5021-5022.

40. McLafferty, F. W.; Bente, P. F. III.; Kornfeld, R.; Tsai, S.-C.; Howe, I. Collisional Activation Spectra of Organic Ions. J. Am. Chem. Soc. 1973, 95, 2120-2129.

41. Bjørnholm, T.; Hammerum, S.; Kuck, D. Distonic Ions as Reacting Species. J. Am. Chem. Soc. 1988, 110, 3862-3869.

42. Spengler, B. Post-Source Decay Analysis in Matrix-Assisted Laser Decomposition/Ionization Mass Spectrometry of Biomolecules. J. Mass Spectrom. 1997, 32, 1019-1036.

43. Jennings, K. R. The Changing Impact of the Collision-Induced Decomposition of Ions on Mass Spectrometry. Int. J. Mass Spectrom. 2000, 200, 479-493. 